\title{
Anthropological Study of Ethno-medicine in Gash Barka Region, Western Eritrea
}

\author{
Senait Bahta \\ Department of Anthropology and Archaeology, Adi-Keih College of Arts and Social Sciences, Eritrea
}

Received October 8, 2019; Revised December 10, 2019; Accepted December 17, 2019

Copyright $\bigcirc 2020$ by authors, all rights reserved. Authors agree that this article remains permanently open access under the terms of the Creative Commons Attribution License 4.0 International License

\begin{abstract}
The indigenous community of Gash Barka region, Western Eritrea has vast knowledge of their biodiversity. They use plant medicine to treat and prevent ailments. Their traditional therapeutic practices reveal that treatment takes a holistic approach and diseases are preventable. Whenever a person is affected, all community members are treated, with children getting smaller portion of the medicine. Also the focus of treatment is not only biological but also social and psychological. Endowed with rich biodiversity, the community uses plant medicine to treat ailments. The same medicinal plants are used to treat different ailments; different ailments are treated by same plant medicine, thus, 'it is the cause not the symptom that is treated'. This paper is an anthropological study of traditional medicine among two indigenous Eritrean groups. Using unstructured interview method, qualitative data has been gathered from knowledgeable men and women, the custodians of the knowledge. The community's perception of health and illness and their knowledge of plant medicine's application is then described in detail using a descriptive method. It is concluded that traditional medicine is a life-tested knowledge of affordable/available homemade medicine with multiple values including developmental, utilizing local resources, heritage and biodiversity conservation. The significance of documenting and upgrading this time-tested knowledge for a sustainable future should not be overlooked.
\end{abstract}

Keywords Ethno-medicine, Medicinal Plants, Holism, Indigenous

\section{Introduction}

Every society has its own perception of health and illness and its own therapeutic system to prevent and cure different ailments. Compared to allopathic medical system, this locally acquired traditional medical system is part of all human cultural systems. It is holistic, in that the cause treated is not only biological but includes others such as environment and spiritual in accordance with customs of the specific community. Each is believed to have an impact on the wellbeing of a person and, therefore, has a corresponding local traditional treatment. This being the case, the patient's physical, social and spiritual well-being is the focus of the therapeutic practice. The community relies on nature, and its biodiversity as a source of medicine as well as for preventive measures against the spread of diseases. Indicating the timeless value and culture-specific nature of traditional medicine research shows that,

Traditional medicine, variously known as ethnomedicine, folk medicine, native healing or complementary and alternative medicine, is the oldest form of health care system that has stood the test of time. ${ }^{1}$

The communities under study, the Nara and the Kunama, who reside in the Gash Barka region, Western region of Eritrea have a long history of herbal medicine on which they still depend. ${ }^{2}$ This research paper is a description of their perceptions of disease and health and their knowledge of medicinal plants. The communities are known for their wide use of medicinal plants. Their rich ecology provides them with rich biodiversity. Indeed, with the two perennial rivers in the country, Gash and Setit rivers, located in their environment, there is an abundance of both plant and animal species. The wealth of biodiversity is not limited to quantity but it is also a source of knowledge as the research tries to show. A survey on traditional healers in the country shows that, out of 3980 practitioners in the whole country, 1048 , or $22 \%$ are located in the Gash Barka region. ${ }^{3}$

This research paper has five parts: Part I is general introduction; Part II is background to the study area and the

\footnotetext{
1 Abdullahi A. 2011:115

2 Yemane B. 2017:40

3 Andemariam, W. S. 2010:130
} 
communities under study; Part III is a brief outlook of the communities' perception of illness and health; and Part IV is a description of their traditional medicinal knowledge and therapeutic practices. Part V is the conclusion and includes recommendations supporting similar research in the area, that have called for traditional medicinal knowledge's recognition, institutionalization, and upgrading through scientific studies.

\section{A Brief Ethnography of the Kunama and the Nara}

The Kunama and the Nara communities are two indigenous groups in Eritrea. They originally came from the Central Nile Valley region and today they live in the area between the Gash and Setit rivers in Southwestern Eritrea. They both speak Nilotic languages that belong to the Nilo Saharan Language family. A mixed population displaying characteristics of both cultures also live at the head of the Barka tributaries. They live together peacefully as neighbors. The Nara are followers of Islam and the Kunama follow three different religions - traditional ancestral worship, Islam and Christianity. They are both agriculturalists with a mix of pastoralism, enjoying the abundance of their natural environment. They use an extensive farming method because the population density is low compared to that of the highland region in the country, who use intensive farming, which is typical of high populated regions.

\subsection{Social Organization}

The social organization of the two groups differs. The Nara community is patrilineal and their social organization is in the male line. All men and women who count a common ancestor through their father belong to one patrilineal descent group. Geographically, they are organized into four sub-groups:
1) Nara Hegir
2) Nara Mogeraib
3) Nara Endrta
4) Nara Koita.

The Kunama's social organization is matrilineal, that is, descent is through the mother's line. All men and women who belong to the same matri-lineage and who count a common ancestress through their maternal line live in one group. Geographically, like the Nara, they are also organized in four sub-groups each with its separate symbol and social role in the community:
1) Karawa (Moon)
2) Shuwwa (Hippopotamus horn)
3) Gurma (Ivory)
4) Serma (Rhino's horn).

Each sub-group has a symbol representing it - a moon, an ivory, a rhino's horn or a hippopotamus' horn, which is placed at the entrance of the respective member's house, distinguishing it from the others. Each sub-group has a different social function in the society.

The Kunama's matrilineal system makes women relatively less rigid in their division of labour. While it is rare to see a woman in patrilineal groups in Eritrea ploughing land and doing all the farm work without the help of a man, it is common to see a Kunama woman and her young son or daughter working on their farm land without the assistance of an adult male.

Although there are differences between the Kunama and the Nara, their similarities abound. Both have periodic rites such as to propitiating the fertility of their crops regulated by Furda Manna - "ruler of the earth" - with the assistance of special shamans who have a role assigned by hereditary right. The shamans are believed to be the regulator of rain, protectors against locust, protectors against birds, protectors against worms and protectors against flies. This is part of both communities' culture of conserving their biodiversity.

\subsection{The Ecological Environment of Gash Barka}

The Gash Barka region located in the South Western Lowland, is one of the six agro-ecological zones in the country. It has low population, mass biodiversity and fertile soil that is fed with two perennial rivers. Bein E. (1996) writes:

The topography is flat, and the climate hot and semi-arid, mean monthly temperature ranging from 29 to $23^{\circ} \mathrm{C}$. It is a flat area, hot and semi-arid and lies at an altitude of 600-750 masl. Vertisol soils are predominant. It is a vast region with rich biodiversity. Rainfall is reliable even though only 400-600 mm per annum. Population density, both of people and livestock is low. Extreme climatic variation does not occur. ${ }^{4}$

The crops that grow in this region are drought-resistant and include sorghum, pearl millet and sesame. Fruits and vegetables are also cultivated. Murtaza M. (1998), writing on peasant and pastoral communities in Eritrea's Gash Barka communities, states that the Gash Barka communities, combining agro-pastoralism in their vast and bio-diverse region, enjoy viability, vulnerability and adaptability based on a combination of agriculture and pastoralism their rich ecological environment allowing them to practice mixed economy with enough natural resources for herding and farming, giving them sufficient returns of food supply. ${ }^{5}$

Human life is linked to the natural resources that sustain all life on earth. Our ancestors depended on multiple nutrients and had mobile life style with a good health status, free from today's chronic diseases that attack human

4 Bein E. 1996:9

5 Murtaza 1998:38 
beings. Conserving bio-diversity is, therefore, conserving human life on earth. As it were, what we live today is what was done fifty years ago and what we do today will be felt by those who will live fifty years from now. The Gash Barka communities, who are aware of the above fact, have a tradition of conserving their rich natural environment, which is the source of their food and medicine, as well as other useful raw materials essential for their daily life. For instance, according to their custom, trees that are very useful for the community are not cut and collected by women for fire. This information is passed to the women of the community on the day of their marriage as part of the orientation about their responsibility in their new home.

\subsection{Map of the Study Area}

The Gash Barka region, the southwestern region of Eritrea, is home to the Kunama and Nara communities.

TheYellow shaded part is Gash Barka region, the study site where the indigenous Kunama and Nara communities live in Eritrea.

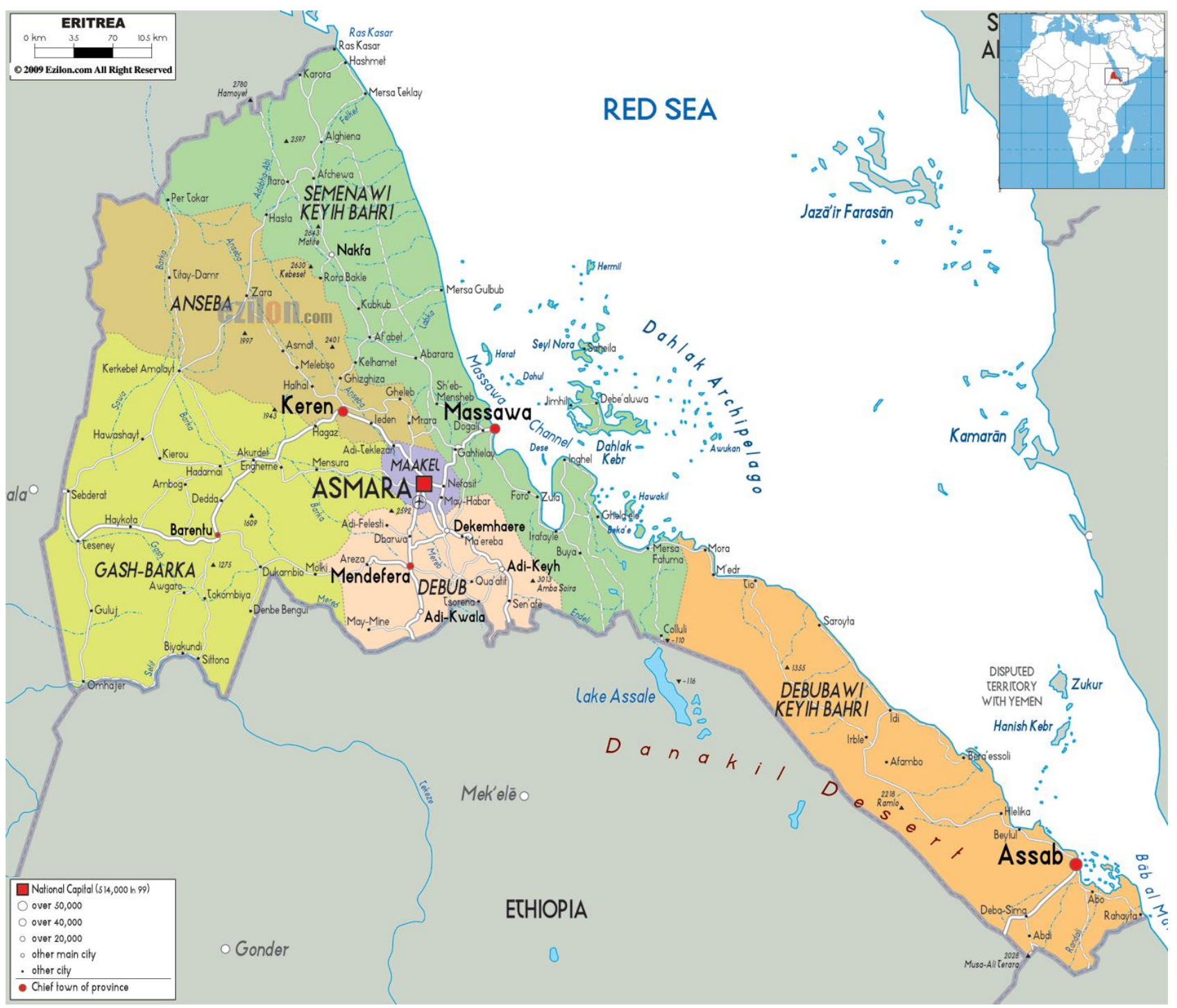

Source: Taken from Google 


\section{Perception of Disease and Therapeutic Practices in Gash Barka Region}

The habitat of the Gash Barka communities is in close proximity to the two main rivers, Gash and Setit. As a result, the main health problems in the communities are linked to semi-arid, hot weather condition and water-borne diseases. They include malaria, intestinal infection, TB, diarrhea, tapeworm, urinary tract infection etc. During the hot season, the communities also experience dehydration as they walk long distances for a long time under the sun, to and from their farmland or to fulfill other family responsibilities as part of their daily chore. Their traditional health practices are also related to the above stated ailments because in coping with the health hazards they have developed the types of treatment. The communities' perception of illness and health is, therefore, linked to the type of natural environment and the daily activities they lead in their day to day life. Even though much has changed in recent years as a result of health care projects to improve the communities' health status, both by the government and other organizations that work on improving communities' health, the prevalence of $\mathrm{TB}$, malaria, infections including sunstroke and others used to be high and a burden to human lives.

The communities believe that three main factors affect their health: environmental (for example, a disease they refer to as Enthab is believed to be caused by the hot and semi-arid weather and/or having bathed after walking outside); biological (the bacteria/insects or other biological bodies that bite their skin and bring disease to them); and spiritual factors which (mainly refer to mental or psychiatric problems that they see as coming from spirits around them, to punish one who crosses the norms and values of the ancestors). Each factor has an impact on the communities' wellbeing and has a corresponding local traditional treatment. Therefore, the communities rely on their biodiversity as a source of their medicine. However, they also have their own local preventive measures against the spread of disease in their communities.

In a monograph titled Furda (2010), written by Santina Debessai, a native to the study area in Gash Barka, it is asserted that:

...the communities' knowledge is not limited only to the medicinal use of the trees but also ... causes of diseases and how to treat them. They have traditional medics who check on the villages' health condition. Some of these traditional medics tour around the village by night to study the villagers' health condition. If they hear any unusual sound such as coughing or so, they treat the whole village as a whole.... If there is a sign of any skin disease, they give every villager medicine to wash with.... They even follow the livestock's and the plants' health condition.... They control insects and they try to cure whatever comes on the way to the village's wellbeing by using different types of medicine. .. They are treated all at once in a big compound, mostly early morning hours, adults take twice that of the children's, who get less of the medicine in a small tafara (a round wooden container), or if it is something to wash with, they wash their bodies with the medicine. This is taken as a kind of vaccine. ${ }^{6}$

The researcher explains further the communities' perception of the disease as communicable but also preventable as can be observed in their practices to cope with daily life, protecting the community as a whole:

When people go from a village to another village, and on their way back home, they don't soon enter their village and join their families, until the flies they carried on their clothes from the other village are removed from their bodies, and so they sit for a while until the flies go off to the trees around. If a member of the village gets unusual type of disease, he is secluded in a separate hut and food is given to him under the door. No one is allowed to enter his place and the way to his place is closed with thorny bush. $^{7}$

Among the Nara communities, a similar perception of health and diseases can be observed. A knowledgeable Nara traditional medic in Areda village of Gash Barka region said in an interview, Ethnomedicine has existed since the beginning of human societies. We, the practitioners own it either through natural gift or through informal training from older family members. Different means are used to treat people, including religious means like prayers, or plant parts such as seeds, barks, leaves, roots and flowers and also food types such as soup from plants or animals' bone. The types of diseases treated using traditional medicine are also not limited.

The practitioner also identified the weather condition, the muddy or swampy environment as well as some spiritual actors as causes of disease. Each cause is treated using plant medicine applicable to the specific cause according to the traditional knowledge and belief that has helped the communities and their ancestors to survive in and cope with their respective human and natural environment.

\section{The Kunama and Nara Traditional knowledge on Plant Medicine}

The indigenous communities of Gash Barka region have extensive knowledge of medicinal plants and depend mainly on them for their health. Previous studies have shown that, in terms of taking treatment using plant medicine, the communities under study represent almost one third of the country's uses of medicinal plants. This

6 Santina D. 2010:67
7 Ibid 
confirms the rich indigenous knowledge of the Gash Barka communities about medicinal plants and their uses. The researcher was also able to learn during the interviews that the communities' use not only plants but also wildlife for various medicinal purposes. For instance, soup of some specific animals is believed to be medicinal while certain parts of animal bodies are used for treatment of certain ailments.

A study of traditional medicine is underway in Eritrea, which is led by the University of Asmara's Medicinal Plant Drug Discovery Centre (MPDDRC). The MPDDRC has done a reliable and initial survey on the number of traditional healers. The survey shows that the number of practitioners in the whole country is 3980, and Gash Barka region, the study site in this research, is the second largest in the country in terms of the number of diversity of traditional practices, and the number of traditional practitioners. The survey also shows that out of the total 3980 traditional practitioners identified in the country so far, 1048 or $22 \%$ are located in Gash Barka. ${ }^{8}$

The relevance and validity of traditional medicine and therapeutic practice in indigenous communities as a whole is indicated in other research on the area. For instance, various studies on medicinal plants in Ghana affirm the efficacy of ethnomedicine on balancing the human body throughout the centuries before biomedicine. In line with what is argued in this research, the studies also indicate that proper scientific analysis should be done to upgrade traditional medicine to meet present days' requirement and become available at the global market.

Research on Ethiopian traditional medicine shows that traditional medicine is playing a significant role in caring for human and livestock health and that it has several advantages over imported medicine:

In Ethiopia, traditional medicine has played a significant role in treating health problems in both livestock and humans. Knowledge of medicinal plants of Ethiopia and their uses provides vital contribution to human and livestock health care needs throughout the country. The plant-based human and livestock health care persists and remains as the main alternative treatment for different ailments in Ethiopia, largely due to shortage of pharmaceutical products, prohibitive distance of the health service stations, unaffordable prices by small holder farmers and pastoralists for conventional drugs, emergence and re-emergence of certain diseases and appearance of drug resistant microbes and/or helminths. ${ }^{9}$

A UNDP report states (UNDP 2004):

Women, especially in developing countries, are the farmers, the feeders and the carers in their communities relying on an intimate understanding of nature to fulfil their many and varied roles. ...Female members of a community often bear the brunt of a natural disaster, such as famine or drought, and are the ones who shoulder the responsibility for keeping offspring alive. ${ }^{10}$

In the study communities, women's knowledge of plant medicine is distinct. For instance, from one tree alone, (Oma in local language) Hyphaene thebatica, the Kunama women make multiple uses for their households. The seed is collected to serve as food, palm wine is extracted from the tree's trunks and its bark is leached for medicine. The tree is also used in making preservatives, for sanitizing water bores, as medicine for livestock and as anti-insect in crop storages. The diverse plant types in the Kunama vicinity can be understood in this sense, and they indeed are 'spring boards of knowledge for the communities'.

The use of plants as part of the natural resources can result in economic development. Using scientific research, including laboratory methods, the efficacy and side effect of the medicinal plant can be studied. This is what this paper aims to communicate. Through collaborative interdisciplinary work, various communities can use their natural and local human resources to help get a better condition of life and economic gains.

Reverend Asfeha, a knowledgeable Eritrean elder, in his review of a monograph on Eritrean traditional medicine written in the local Tigrigna language, affirms and emphasizes the need for organizing the local knowledge on traditional medicine; "Our traditional knowledge on medicinal plants should not be left only to those who own or know it, but should be studied and examined thoroughly to change it into modern medicine with clear dosage and prescription and bring it for use by all...". ${ }^{11}$

The need to upgrade traditional medicinal knowledge and conserve its valuable service to the local communities is stressed by research in a similar field.

Traditional medicine has remained as the most affordable and easily accessible source of treatment in the primary healthcare system of resource poor communities and the local therapy is the only means of medical treatment for such communities. ${ }^{12}$

Scientific study of past wisdoms in all aspects of life can be a stepping stone towards a real sustainable development. Without developing through research our traditional medical systems, there can be no other route to flourish the livelihood of local communities and so no way to sustainable development. Genuine effort in this area will need the collaboration of scholars and researchers of all disciplines.

Table 1 shows a list of some medicinal plants that were named by the villagers in Gash Barka

10 UNDP 2004

11 Rev Asfha M. 2019:16

12 Yinger H. 2007:1 
Table 1. Selected Sample Medicinal Plants in Gash Barka Region, Western Eritrea

\begin{tabular}{|ll|l|}
\hline \multicolumn{2}{|c|}{ Botanical Name } & \multicolumn{1}{|c|}{ Uses } \\
\hline 1. & $\begin{array}{l}\text { Dischrosta } \\
\text { chyscinerea }\end{array}$ & $\begin{array}{l}\text { Bark soaked and the water drunk for } \\
\text { easing pain }\end{array}$ \\
\hline 2. & $\begin{array}{l}\text { Ziziphus spina } \\
\text { Christi }\end{array}$ & $\begin{array}{l}\text { Leaf soaked and drunk as anti-sun stroke } \\
\text { or used to wash hair as anti-dandruff }\end{array}$ \\
\hline 3. & Albizia amaara & Leaves used to treat measles \\
\hline 4. & $\begin{array}{l}\text { Balanitesa } \\
\text { egyptiaca }\end{array}$ & $\begin{array}{l}\text { Leaves and seeds oily content drops to } \\
\text { treat ear pain }\end{array}$ \\
\hline 5. & $\begin{array}{l}\text { Tomarindus } \\
\text { indica }\end{array}$ & Pulp used as laxative and anti-insect \\
\hline 6. & $\begin{array}{l}\text { Bosica } \\
\text { senegalensis }\end{array}$ & Roots as nutritious food \\
\hline 7. & $\begin{array}{l}\text { Grewia } \\
\text { flavescens }\end{array}$ & Seed and roots as child skin disease \\
\hline 8. & $\begin{array}{l}\text { Hyphaene } \\
\text { thebaica }\end{array}$ & Leaves for curing cold \\
\hline
\end{tabular}

Traditional medicinal knowledge is culture related. Apart from being diverse and part of all human culture and, therefore, specific, the knowledge can be shared and adopted in a way that it can be used in line with the local knowledge already in place. That is what South-South research collaboration can be useful for. A simple comparison of the uses medicinal plants in two societies can help see the diverse uses of the same medicinal plant.

Ghana is a country in Western Africa where various biodiversity and species of plants are found. A Centre for Scientific Research on Plant Medicine (CSRPM) was formed in 1975 and at present is supplying the communities with herbal medicines of various types. Though the Centre has strategic interest to work on collaborative projects across Africa, for better production of more and better plant medicines, at present it functions as one of its type in West Africa.

Comparing the Gash Barka communities' ethnomedicine with that of Ghana gives us a clear vision that local knowledge is practical but varies in that the same plants used as medicine in both societies are used to treat different ailments. The fact that the medicinal plants can be used to treat varied types of diseases shows that the ethnomedicine of different societies can be exchanged to provide wider service to the different communities. The variation in the use of traditional medicine may be due to the fact that it is produced in response to the specific conditions surrounding the two communities.

Some common medicinal plants and their different uses in Ghana and Eritrea are presented below in Table 2.

Human beings have the capacity to know and to create, innovate or produce some medicine from something else. Indeed, using medicinal plants by processing them in varied ways is human.

Finally, it is important to note that all human communities have acquired knowledge of their plants' uses, and particularly their uses for keeping human beings' good health, which has enabled them to survive the changing environment through the centuries. Such valuable knowledge should be preserved, shared and passed to not only generations of a particular community through direct or indirect methods of culture transmission, but must also be shared with communities in the other regions to benefit all human beings by applying the valuable cultural knowledge that has been sustained up to our time.

Table 2. Comparison between Some Common Medicinal Plants in Ghana and Eritrea

\begin{tabular}{|c|c|c|}
\hline \multicolumn{3}{|c|}{ Uses } \\
\hline Botanical Name & Ghana & Eritrea \\
\hline $\begin{array}{c}\text { Balamites } \\
\text { aegyptiaca }\end{array}$ & $\begin{array}{c}\text { Abdominal pain, } \\
\text { malaria, worms }\end{array}$ & Ear pain, malaria \\
\hline $\begin{array}{c}\text { Diospirosme } \\
\text { spiliformis }\end{array}$ & $\begin{array}{c}\text { Anti infection \& dental } \\
\text { abscess }\end{array}$ & Anti pain \\
\hline $\begin{array}{c}\text { Hyphaene } \\
\text { thebaica }\end{array}$ & $\begin{array}{c}\text { Dracontiasis } \\
\text { indica }\end{array}$ & $\begin{array}{c}\text { Against cold \& } \\
\text { anti pain }\end{array}$ \\
\hline $\begin{array}{c}\text { Tamarindus } \\
\text { Ziziphus } \\
\text { spinachristi }\end{array}$ & $\begin{array}{c}\text { Anti-infection \& } \\
\text { prostate }\end{array}$ & $\begin{array}{c}\text { Against sunstroke } \\
\text { dandruff }\end{array}$ \\
\hline
\end{tabular}

The Nara and Kunama ethnomedicne or traditional knowledge of plant medicine teaches that almost all food plants are nutroceuticals, which means that what is edible is also medicinal. Also, although both men and women have knowledge of medicinal plants types and their uses, men's knowledge tends to be about medicinal plants used as anti venom or anti snake bite and the like while women's knowledge tend to be about internal diseases, including stomach pain, children's diseases such as measles, pregnancy problems, including easing labour gynaecological problems and helping remove the placenta in child birth when there is difficulty. Women's knowledge also includes knowledge about plants that serve as repellants against mosquitoes, cleaning agents in water-wells, and as aromatic plants in traditional sauna or Tish, that after a hard working day helps to ease pain and relax the body muscles.

\section{Conclusions}

The Gash Barka region communities today use traditional medicine, as is elsewhere in the country, even though allopathic medicine is the official medical practice in the country. Research has also shown that the demand for traditional medicine or folk medicine, as it may be referred to elsewhere, is still in high demand by communities for several reasons: It is the practice that the communities can access with relative ease and at affordable price; the communities believe that it can cure diseases and they accept the treatment with no doubt; the patients are not removed from their homes as traditional therapeutic practices often take place in the patients' home or somewhere nearby, where they feel at ease. This is when 
seen from the communities' health benefit. But there are more advantages for upgrading, institutionalizing and standardizing traditional medicine, including conservation of biodiversity and the communities' heritage. The knowledge and skill that have helped communities to survive for centuries, their identity, and the use of local human and natural resources can all lead to the development of own resources, helping avoid dependency. Therefore, it is legitimate to argue that the recognition of the indigenous traditional medicinal knowledge that enhances the communities' identity and gives economic benefit, on top of providing affordable health service to the local communities, is crucial. Hence, the value of conserving and upgrading traditional medicine for sustainable development should not be overlooked.

While the emphasis of this paper is on bringing traditional medicine to an officially accepted scientific level through scientific research, the legal instruments needed for the application of traditional medicine, including the intellectual property rights need to be put in place. So, I support previous research done on the same issue that have called for the 'urgent need for appropriate legal framework', as, indeed, some such legal frameworks are beginning to unfold in some African countries.

\section{REFERENCES}

[1] Abdullahi A. A. (2011) Trends and Challenges of Traditional Medicine in Africa. Africa Journal of Traditional, Complementary and Alternative Medicine (AJCAM). 2011, 8:115 - 123.

[2] Yemane B. et al. (2017). Survey of Some Common medicinal Plants Used in Eritrean Folk Medicine. American Journal of Ethnomedicine Vol. 4 N0. 2. 2017.

[3] Senai W. Mariam. (2010). Legislative Regulation of Traditional Medicinal Knowledge in Eritrea vis a vis Eritrea's Commitments Under the Convention on Biological Diversity: Issues and Alternatives. In LEAD, Environment and Development Journal, Vol.6 No.2.

[4] Bein E et al. (1994). Useful Trees and Shrubs in Eritrea. Identification, Propagation and Management for Agricultural and Pastoral Communities. RSCU/Sida. Nairobi,Kenya.

[5] Murtaza M. (1998). The Pillage of Sustainability in Eritrea, 1600 -1900. Rural Communities and the Creeping Shadow of Hegemony. Westfort. Connecticut.

[6] Santina D. 2010. Furda. Yimesgen Printing Press. Asmara, Eritrea.

[7] Tollosa et al. (2013). Ethno-medicinal study of plants used for treatment of human and livestock ailments by traditional healers in South Omo, Southern Ethiopia. Journal of Ethnobiology and Ethnomedicine, 2013, Vol. 9 No. 32.
[9] Reverend AsfehaMehari 2009. In Himamna Bebahriawi Tsegatatna Nefewes. In Kidane A. Et al. 2009. Published by the Evangelical Lutheran Church of Eritrea.

[10] Yinger H. (2007). Traditional medicinal plant knowledge and use by local healers in Sekoru District, Jimma Zone, Southwestern Ethiopia. Journal of Ethnobiology and Ethnomedicine.

[8] UNDP Report, 2004. 